\title{
Prevalence of Iron Deficiency in Swedish Adolescents
}

\author{
LEIF HALLBERG, LENA HULTEN, GÖRAN LINDSTEDT, PER-ARNE LUNDBERG, \\ ANDERS MARK, JURIS PURENS, BERNHARD SVANBERG, AND BIRGITTA SWOLIN \\ Departments of Internal Medicine, Clinical Chemistry; Clinical Nutrition and Pediatrics. Lniversity of Götehorg. \\ Sahlgrenska Hospital. S-4134.5 Giotethorg, Sweden
}

\begin{abstract}
The prevalence of iron deficiency was determined in Göteborg, Sweden, in a sample of 15- to 16-y-old girls $(n=220)$ and boys $(n=207)$ using serum ferritin (SF). In a recent study in women on the relationship between SF and stainable bone marrow iron, it was established that at a cutoff value for SF of $<16 \mu \mathrm{g} / \mathrm{L}$ in $75 \%$ of women with no iron stores $\mathrm{SF}$ concentration was below this value (sensitivity $75 \%$ ), whereas in $98 \%$ of iron-replete women it was above this cutoff value (specificity 98\%). The present study showed that in $40 \%$ of the girls and $15 \%$ of the boys $\mathrm{SF}$ was below this cutoff value, indicating iron deficiency. Low SF concentration was associated with significant decreases in transferrin saturation, Hb concentration, mean corpuscular $\mathrm{H} \mathrm{Ib}$, and mean corpuscular volume. The results from this cross-sectional study showed that, with decreasing $S F$, the decrease of values for these parameters occurred already before $S F$ had reached the level $16 \mu \mathrm{g} / \mathrm{L}$, suggesting that $\mathrm{SF}$ can be validly used as a single criterion of iron deficiency. Using the cutoff value $\mathrm{SF}<16 \mu \mathrm{g} / \mathrm{L}$, the figures for the prevalence of iron deficiency in adolescents in different countries were compared and found to be rather similar in Australia, Canada, the United States, and Sweden. Iligh iron requirements combined with the present low-energy life-style leading to an insufficient supply of dietary iron may be a reasonable main explanation for the paradoxical, high prevalence of iron deficiency in adolescents in affluent societies. (Pediatr Res 34: 680-687, 1993)
\end{abstract}

\section{Abbreviations}

MCII, mean corpuscular IIb

$\mathrm{MCV}$, mean corpuscular volume

$\mathrm{SF}$, serum ferritin

TS, transferrin saturation

Evidence is accumulating that iron deficiency may impair not only physical activity, especially endurance, but also mental functions such as learning (1-4). Brain iron content increases during the whole of early life and into adulthood. Only $10 \%$ of brain iron is present at birth and $50 \%$ at about the age of 10 , and brain iron content increases up to the age of 20-30 y (5). Animal studies suggest that a lower iron content in the brain due to iron depletion is difficult to restore by iron therapy later (6). Several recent observations have thus increased awareness of the

Received June 17, 1992: accepted April 1, 1993.

Correspondence: Leif Hallberg. Department of Medicine II. University of Göteborg, Sahlgren Hospital, S-413 45 Göteborg, Sweden.

Supported by The Freemason Foundation for Research on Children and Adolescents, Swedish Medical Research Council Project B88-19X-04721-13B importance of preventing the development of iron deficiency (7.8).

Iron requirements are very high in adolescents of both sexes, especially during the growth spurt periods (9). In girls, the menarche imposes further requirements to cover menstrual iron losses (10). In boys, there are also additional needs relating to the increase in $\mathrm{Hb}$ concentration at the time of puberty (11).

Studies on the prevalence of iron deficiency were previously based mainly on $\mathrm{Hb}$ determinations and focused on the prevalence of anemia caused by iron deficiency. The distributions of the classic hematologic parameters of iron status, e.g. Hb concentration, red cell indices ( $\mathrm{MCH}$ and $\mathrm{MCV}$ ), and TS, are wide in normal subjects and show a marked overlap with the corresponding distributions in iron-deficient subjects. These methods can therefore only validly be used when the severity of iron deficiency is marked. In highly industrialized countries where this severity is usually mild, these methods are therefore too insensitive both in the single patient and in epidemiologic studies. This may lead to underestimation of the prevalence of iron deficiency if a reasonably high specificity is ascertained.

The introduction of SF determinations to evaluate iron status made it possible to make more valid estimates of the prevalence of iron deficiency (12). A relationship between SF levels and iron stores is well established, and low SF values are only observed in iron deficiency (13). Some diseases such as infections, liver diseases, and hyperthyroidism, however, may give too high values in relation to iron stores also in iron-deficient subjects. Temporary reduction of caloric intake has the same effect (14). The choice of cutoff value to separate iron-deficient and iron-replete subjects has been difficult, however. Originally, $<12 \mu \mathrm{g} / \mathrm{L}$ was chosen on the basis of a statistical analysis of an extensive sample of 326 adults using certain criteria to select normal subjects (15). More recent studies partly relating SF to findings of stainable iron in bone marrow smears suggested that higher cutoff values should be used and values between 15 and $27 \mu \mathrm{g} / \mathrm{L}$ have been proposed (16-25). In a study in our laboratory on a randomly selected sample of 207 women all aged $38 \mathrm{y}$, we measured both SF and content of stainable iron in bone marrow smears (26). We found that at a cutoff level of $<16 \mu \mathrm{g} / \mathrm{L}, \mathrm{SF}$ had both a high specificity $(98 \%)$ and a hign sensitivity $(75 \%)$, i.e. $98 \%$ of ironreplete subjects (with stainable bone marrow iron; $n=105$ ) had SF values $\geq 16 \mu \mathrm{g} / \mathrm{L}$ and that $75 \%$ of iron-deficient subjects (with no stainable bone marrow iron; $n=69$ ) had values below $16 \mu \mathrm{g} / \mathrm{L}$. In this sample of women, the diagnostic efficiency (correct positive and correct negative results in relation to all results) of $\mathrm{SF}$ at this cutoff value $(<16 \mu \mathrm{g} / \mathrm{L})$ was $91 \%$.

Although a low SF concentration indicates low iron stores, it may be argued that absence of iron stores per se might not be associated with an increased risk of an insufficient supply of iron to tissues: therefore, iron-deficient erythropoiesis, rather than the absence of iron stores, should be the basis used to classify subjects as being iron deficient and developing functional impairments related to this deficiency. Theoretically, this is a logical position. 
The problem, however, is the above-mentioned difficulty in demonstrating in the single, iron-deficient subject significant changes of the classic laboratory parameters that reflect an insufficient supply of iron to the erythropoiesis, due to the marked overlap in laboratory values between normal and iron-deficient subjects. The great intra- and interindividual variation, $e . g$. in TS, makes it impossible, at least at an early stage of iron deficiency, to identify single individuals with no iron stores who also have a compromised supply of iron to tissues.

According to presently generally accepted concepts, the delivery of iron to the erythroid bone marrow will not be inadequate until iron stores are exhausted. Due to the overlapping mentioned, there is no doubt that during the development of iron deficiency it will take some time before an iron-deficient erythropoiesis can be detected in the individual. It is not known, however, whether this inability to establish an iron-deficient erythropoiesis early corresponds to a true intermediate, transitional stage of no functional importance.

In 1990, studies were made in a representative sample of 15to 16 -y-old boys and girls in Göteborg to examine the prevalence of iron deficiency among adolescents and to try to clarify its causes and possible consequences. The purpose of the present paper was limited to studying the prevalence of iron deficiency based on SF determinations. Moreover, the intention was to examine at which SF concentration signs of an iron-deficient erythropoiesis were observed in boys and girls.

\section{MATERIALS AND METHODS}

The present sample was drawn to be representative of 15- to 16-y-old boys and girls in Göteborg covering different socioeconomic and living conditions. Areas were chosen varying from high-income one-family housing to multiapartment houses with lower income families. Göteborg is the second biggest city in Sweden with about 430000 inhabitants. It has Sweden's main port and is principally engaged in trade and industry. The study was done in 1990 in late spring when the incidence of infections is usually low. In 1990, there were in total 5280 boys and girls in the 9th grade. Four schools in different areas were selected, and all 9 th-grade boys and girls in these schools were selected for the study, comprising 260 boys and 255 girls. They were all informed in detail by a specially assigned nurse. Written information was sent via the pupils to all parents, who had to give written approval for the drawing of blood samples. Permission was granted for 220 girls $(86 \%$ of those invited in the original sample) and 207 boys ( $80 \%$ of those invited in the original sample).

$S F$. The SF values used in the study were determined by a double-antibody polyethyleneglycol RIA (Diagnostic Products Corp., Los Angeles, CA). The assay was calibrated against World Health Organization 1st International Standard, IS 80/602. The performance of the RIA in our hands has been reported (14). Judging from results of quality control in a large-scale international immunoassay program, the precision may be classified as good or excellent and the bias is not significantly different from zero (i.e. overall mean). The assays in the present study were done immediately after the completion of the clinical study. In the standard curves, $95 \%$ binding of the radioligand is typically obtained at a concentration of about $3-4 \mu \mathrm{g} / \mathrm{L}$, and $50 \%$ binding at about $90 \mu \mathrm{g} / \mathrm{L}$. Single determinations of the specimens from the participants and duplicate determinations of three different controls (in-house serum pools) at the start and at the end of the assay runs were done. The values for the controls in the three consecutive runs were in good agreement with the values usually obtained. In 42 runs during $1 \mathrm{y}$, the coefficient of variation within assays and the total between assays were as follows: at a mean concentration of $15.2 \mu \mathrm{g} / \mathrm{L}, 6.1$ and $7.1 \%$, respectively; at $63 \mu \mathrm{g} / \mathrm{L}, 3.2$ and $4.1 \%$ respectively; and at $642 \mu \mathrm{g} / \mathrm{L}, 4.3$ and $5.7 \%$, respectively.

Considering the importance of the accuracy and precision of the SF analysis in the present study, all sera were also analyzed using an immunochemiluminometric assay (MagicLite Ferritin, Ciba Corning Diagnostics Corp., Medfield, MA) previously reported to correlate well with the RIA (27). Although our experience of this assay is limited, the results were expected to give further information on the validity of the results obtained with the RIA for which completely different reagents are used.

Itematologic methods. Hb concentration, MCV, MCH, and red cell distribution width were analyzed with an automatic system, Technicon H2 equipment (Technicon Instruments Corp., Tarrytown, NY). Serum iron was determined according to Ichida et al. (28) using bathophenantroline sulfonate as binder. Total iron-binding capacity was determined by adding excess ferroammonium citrate to serum and removing excess iron with the ion-exchanger Amberlite IRA 400 (Rohm and Haas Co., Philadelphia, PA). TS was the ratio of serum iron to total ironbinding capacity expressed as a percentage.

Statistics. All statistical analyses were made using a Statview II computer program (Abacus Concepts Inc., Berkeley, CA) and the Excel Version 2.2 computer program (Microsoft. Redmont, WA). Mean values were compared using the $t$ test. Graphical analysis of data (29) was also done using a specially designed computer program [locally weighted least squared error fit method in Kaleidagraph, Mac II, version 2.1 (Synergy Software, PCS Inc., Reading. PA)].

\section{RESULTS}

The laboratory findings in the total material of boys and girls are given in Table 1. Table 1 also shows the distributions of the laboratory parameters to make possible comparisons with results obtained in other studies $(18,30,31)$. The distributions of log $\mathrm{SF}$ in boys and girls are shown in Figures 1 and 2.

The RIA (Diagnostic Products Corp. method) was used throughout the study and run against an international standard as mentioned in Materials and Methods. The sera were also analyzed using an immunochemiluminometric assay. The mean $\mathrm{SF}$ value with the latter method was $0.64 \mu \mathrm{g} / \mathrm{L}$ lower. The correlation between individual results obtained with the two methods was high, $r=0.984$.

Among the boys, 31 (15\%) of 207 had SF below $16 \mu \mathrm{g} / \mathrm{L}$, and the corresponding values for the girls were $88(40 \%)$ of 220 . Judged visually, there was a bimodal distribution of the values for $\log$ SF concentration in the boys, with some skewness to the left. In the girls, there was also some skewness to the left that might reflect the two groups of iron-replete and iron-deficient girls.

Different analyses were made to examine the relationship between iron stores and the presence of iron-deficient erythropoiesis. The material was divided into three groups for each sex based on expected iron status: group I, with $\mathrm{SF}<16 \mu \mathrm{g} / \mathrm{L}$, was considered to contain almost exclusively iron-deficient subjects. Group III, with SF $>30 \mu \mathrm{g} / \mathrm{L}$, was expected to contain mainly iron-replete subjects. Group II, with SF between 16 and $30 \mu \mathrm{g} /$ $\mathrm{L}$, was an intermediate group. This group can be estimated to contain mainly normal subjects, but about $10-30 \%$ of the total number of subjects in this group may be iron deficient. This division was based on results in a previous unpublished study in 203 women on the relationship between SF and stainable iron in bone marrow smears showing that only $2 \%$ of normal subjects have SF $<16 \mu \mathrm{g} / \mathrm{L}$, about $25 \%$ of iron-deficient subjects having SF values above this level but only $6 \%$ having $\mathrm{SF}$ values $\geq 30$ $\mu \mathrm{g} / \mathrm{L}$.

The hematologic findings in these groups are shown for girls in Table 2 and for boys in Table 3. It was evident that $\mathrm{Hb}$ concentration, TS, MCH, and MCV were significantly lower in the iron-deficient group (group I) compared with the other two groups (groups II and III), both when the groups were compared separately and when groups II and III were pooled. Comparisons between groups II and III showed a significant difference only 
Table 1. Distribution of different laboratory parame'ters in whole samples of hous and girls

\begin{tabular}{|c|c|c|c|c|c|c|c|c|}
\hline & \multirow[b]{2}{*}{ Mean } & \multirow[b]{2}{*}{ SD } & \multirow[b]{2}{*}{$n$} & \multirow[b]{2}{*}{10 th } & \multicolumn{3}{|c|}{ Percentile } & \multirow[b]{2}{*}{90 th } \\
\hline & & & & & $25 \mathrm{th}$ & 50 th & $75 \mathrm{th}$ & \\
\hline \multicolumn{9}{|l|}{ Boys } \\
\hline Itb $(\mathrm{g} / \mathrm{L})$ & 147 & 8.31 & 203 & 135 & 142 & 147 & 152 & 157 \\
\hline TS $(\%)$ & 32.7 & 10.25 & 197 & 21.2 & 25.7 & 31.7 & 38.6 & 46.3 \\
\hline $\mathrm{MCH}(\mathrm{pg})$ & 29.4 & 1.43 & 203 & 27.7 & 28.6 & 29.2 & 30.2 & 31.0 \\
\hline MCV (fl) & 88.4 & 3.87 & 203 & 83.5 & 85.5 & 88.1 & 90.9 & 93.2 \\
\hline $\operatorname{RCDW}\left(\sigma^{\circ}\right)^{*}$ & 13.0 & 0.95 & 202 & 12.3 & 12.5 & 12.9 & 13.2 & 13.5 \\
\hline $\mathrm{SF} \mu \mathrm{g} / \mathrm{L}$ & $26.4 \dagger$ & $1.71 \ddagger$ & 207 & 13.2 & 22 & 29 & 40.8 & 52 \\
\hline \multicolumn{9}{|l|}{ Girls } \\
\hline $\mathrm{Hb}(\mathrm{g} / \mathrm{L})$ & 134 & 7.6 .3 & 216 & 123 & 129 & 134 & 139 & 143 \\
\hline TS $(\%)$ & 29.9 & 10.7 & 215 & 17.2 & 22.8 & 29 & 35.2 & 43.4 \\
\hline $\mathrm{MCH}(\mathrm{pg})$ & 29.6 & 1.43 & 215 & 27.8 & 28.8 & 29.5 & 30.6 & 31.3 \\
\hline $\mathrm{MCV}(\mathrm{fL})$ & 90.1 & 3.80 & 216 & 84.8 & 87.6 & 90.3 & 92.8 & 94.8 \\
\hline $\operatorname{RCDW}(\%)$ & 12.8 & 0.71 & 217 & 12.1 & 12.4 & 12.7 & 13.2 & 13.6 \\
\hline $\mathrm{SF}(\mu \mathrm{g} / \mathrm{L})$ & $18.2 \dagger$ & 1.987 & 220 & 7.5 & 12 & 18.2 & 28.5 & +1.5 \\
\hline
\end{tabular}

* RCDW, red cell distribution width.

t Geometric means.

$¥$ Antilog of logarithmic values.

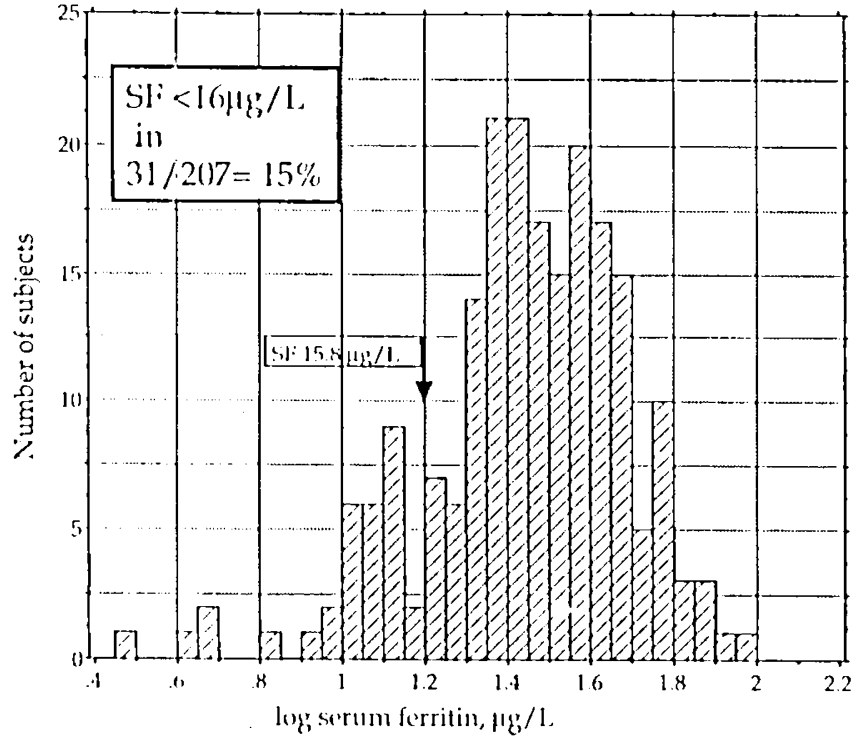

Fig. 1. Distribution of log SF concentration in 207 boys aged 15-16 y. $\log$ SF $16=1.2: 20=1.3: 30=1.48: 40=1.6$.

for $\mathrm{Hb}$ concentration. No significant differences were seen for red cell distribution width.

In another analysis of the relationships between SF and iron status parameters, the materials for boys and for girls were divided into deciles for SF concentration, and means for $\mathrm{Hb}$ concentration, $\mathrm{MCH}, \mathrm{MCV}$, and TS were calculated in each decile. The results in the graph in Figure 3 show the decile values of these parameters at the mean SF concentration in each decile. With decreasing SF, there is a consistent decrease in all four parameters. Visually, the decrease seems to start well above the cutoff value for $\mathrm{SF}<16 \mu \mathrm{g} / \mathrm{L}(\log$ value 1.2$)$ in both boys and girls. Analyzing the linear regression between the hematologic parameters and $\log \mathrm{SF}$ in the range covering the seven lowest SF deciles (to SF $26 \mu \mathrm{g} / \mathrm{L}$ in girls and $37 \mu \mathrm{g} / \mathrm{L}$ in boys), the correlation coefficients for $\mathrm{MCH}, \mathrm{MCV}, \mathrm{Hb}$ concentration, and $\mathrm{TS}$ were all significant. The $p$ values for boys were $<0.01,<0.01$, $<0.01$, and $<0.02$, respectively. The corresponding $p$ values for the girls were $<0.01, N S,<0.02$, and 0.05 , respectively. To obtain further information about the SF concentration at which the hematologic parameters started to decrease, the data were also analyzed graphically using the weighted least square fit method and a special computer program (Fig. 4). This method is less

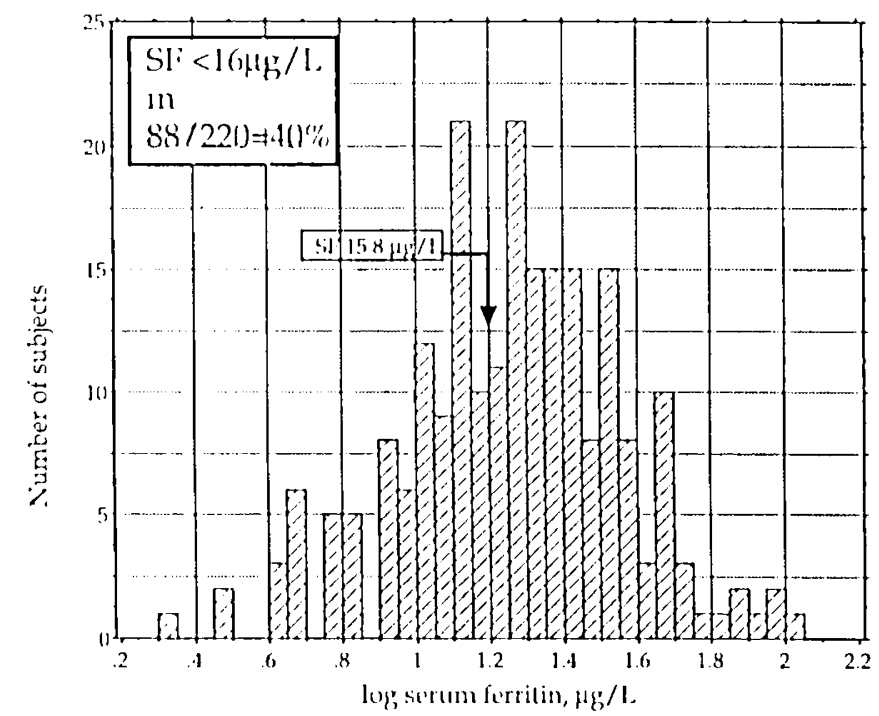

Fig. 2. Distribution of $\log \mathrm{SF}$ concentration in 220 girls aged 15-16 y. $\log \operatorname{SF} 16=1.2: 20=1.3 ; 30=1.48: 40=1.6$.

sensitive for single outliers. For the girls, there was a continuous decrease in $\mathrm{Hb}$ concentration, $\mathrm{MCH}, \mathrm{MCV}$, and TS at least from $\log$ SF 1.3 and possibly from log SF 1.4, thus corresponding to an $\mathrm{SF}$ concentration of about $20 \mu \mathrm{g} / \mathrm{L}$. For the boys, the continuous decrease in hematologic values started already at $\log$ SF 1.5 or even higher, i.e. in the SF range $30-40 \mu \mathrm{g} / \mathrm{L}$.

The results from these studies indicate that, with decreasing SF, signs of an iron-deficient erythropoiesis already appeared before SF had reached the level $(<16 \mu \mathrm{g} / \mathrm{L})$ considered to be associated with depleted iron stores.

Common infections, such as a common cold with fever, may increase the SF level (32-34). For this reason, the number of subjects in the different groups who had a history of upper respiratory infection during the preceding month (Table 4) were recorded. A $\chi^{2}$ analysis showed that the frequency of infections was higher in the groups with $\mathrm{SF} \geq 16 \mu \mathrm{g} / \mathrm{L}$, suggesting that preceding infections had to some extent shifted the SF values upward.

\section{DISCUSSION}

Iron status is best described as a continuous variable from iron overload to different degrees of iron depletion in different tissues. 

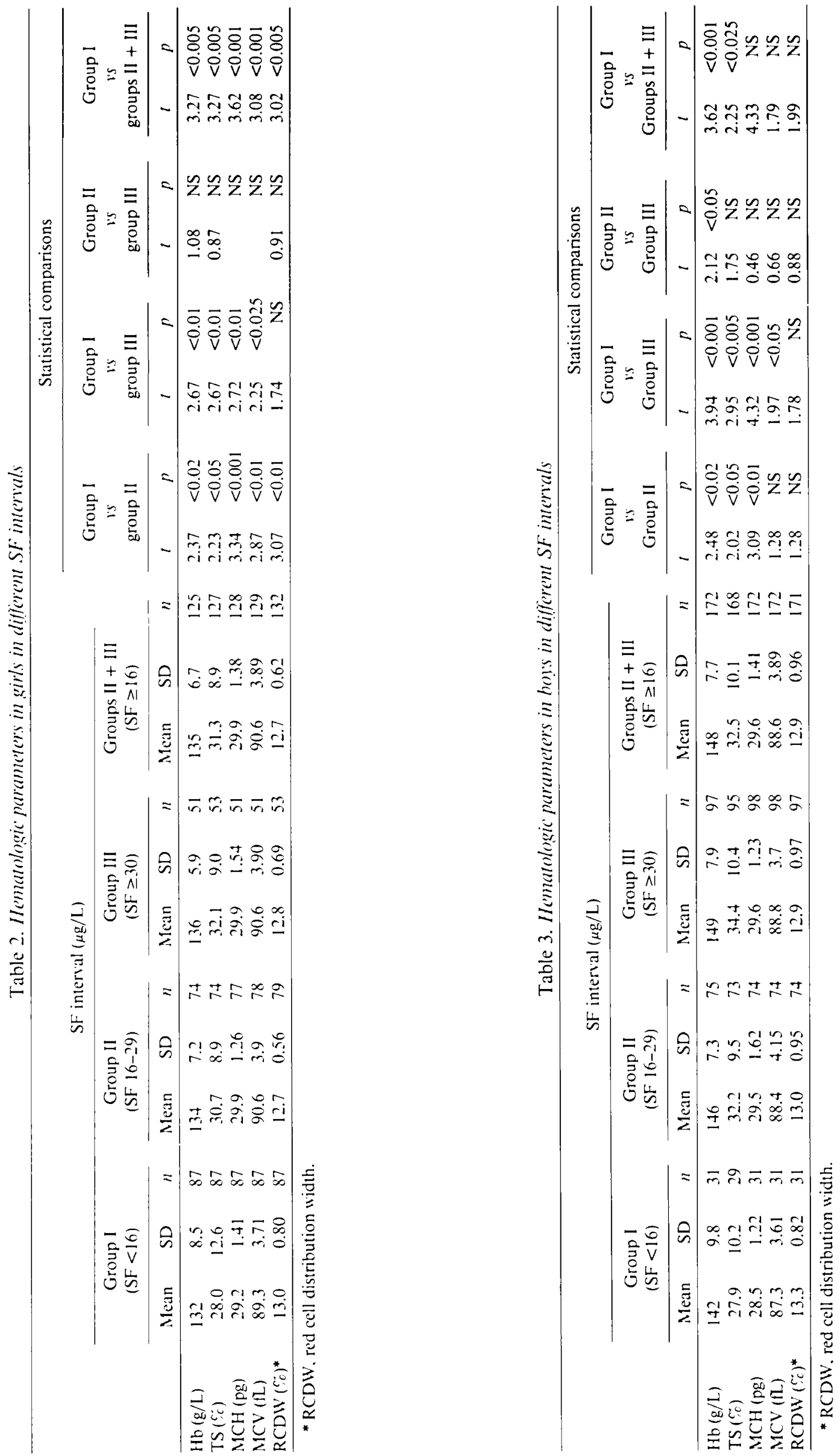

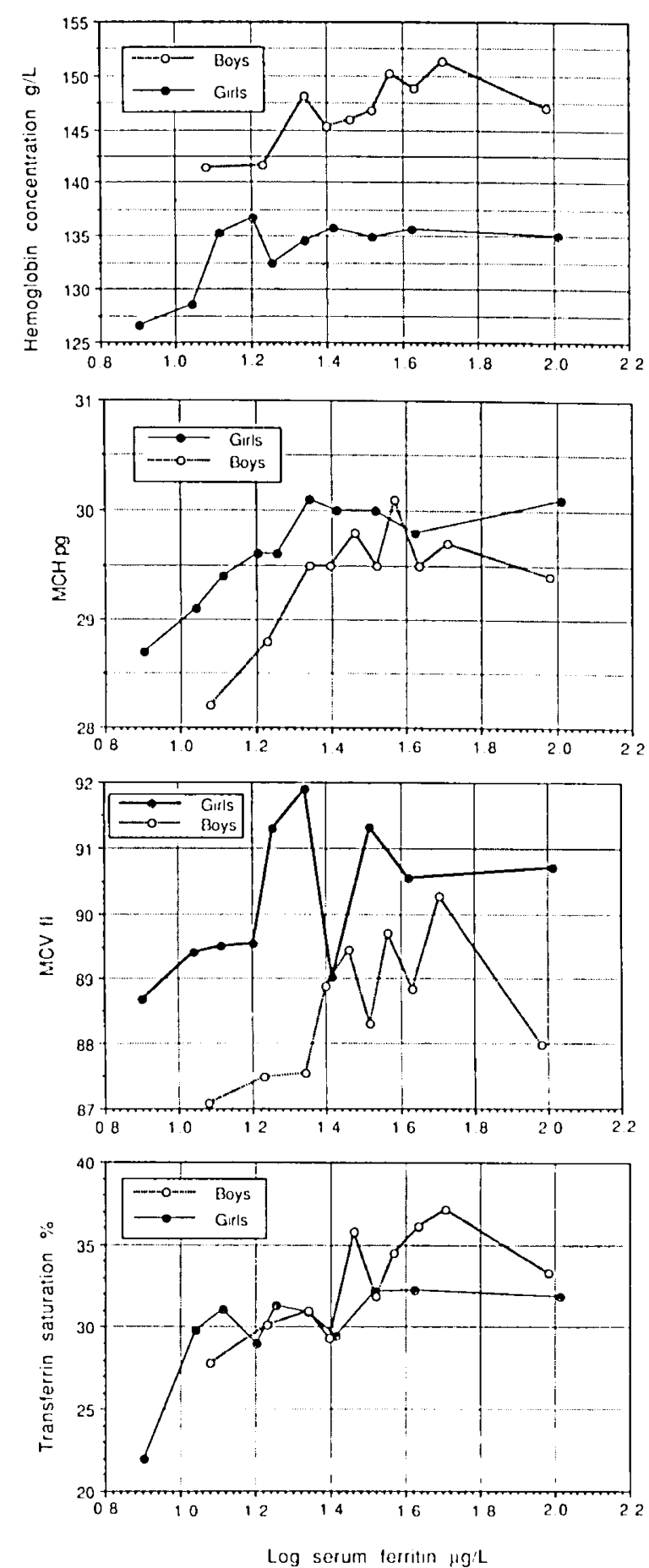

Fig. 3. Hb concentration, $\mathrm{MCH}, \mathrm{MCV}$, and $\mathrm{TS}$ in relation to $\log \mathrm{SF}$ concentration in girls and boys. The materials of boys and girls were divided into deciles based on $\log$ SF concentration. In each decile, the mean values for the hematologic parameters were plotted against the mean $\log \mathrm{SF}$ value in each decile. $\log 16 \mu \mathrm{g} / \mathrm{L}=1.2$ (for decision limit for $\mathrm{SF}$ concentration, see text). $\log \mathrm{SF} 16=1.2 ; 20=1.3 ; 30=1.48 ; 40$ $=1.6$.

Empty iron stores are just a point on this scale of importance for two reasons. One is that the supply of iron to tissues from this point downward may be compromised; the other is that this point is conceptually easily definable and also readily detectable by laboratory methods such as the absence of stainable iron in bone marrow smears and by a low SF.

As mentioned, the cutoff value for SF used $(<16 \mu \mathrm{g} / \mathrm{L})$ was based on a study in 38 -y-old women in whom iron status was
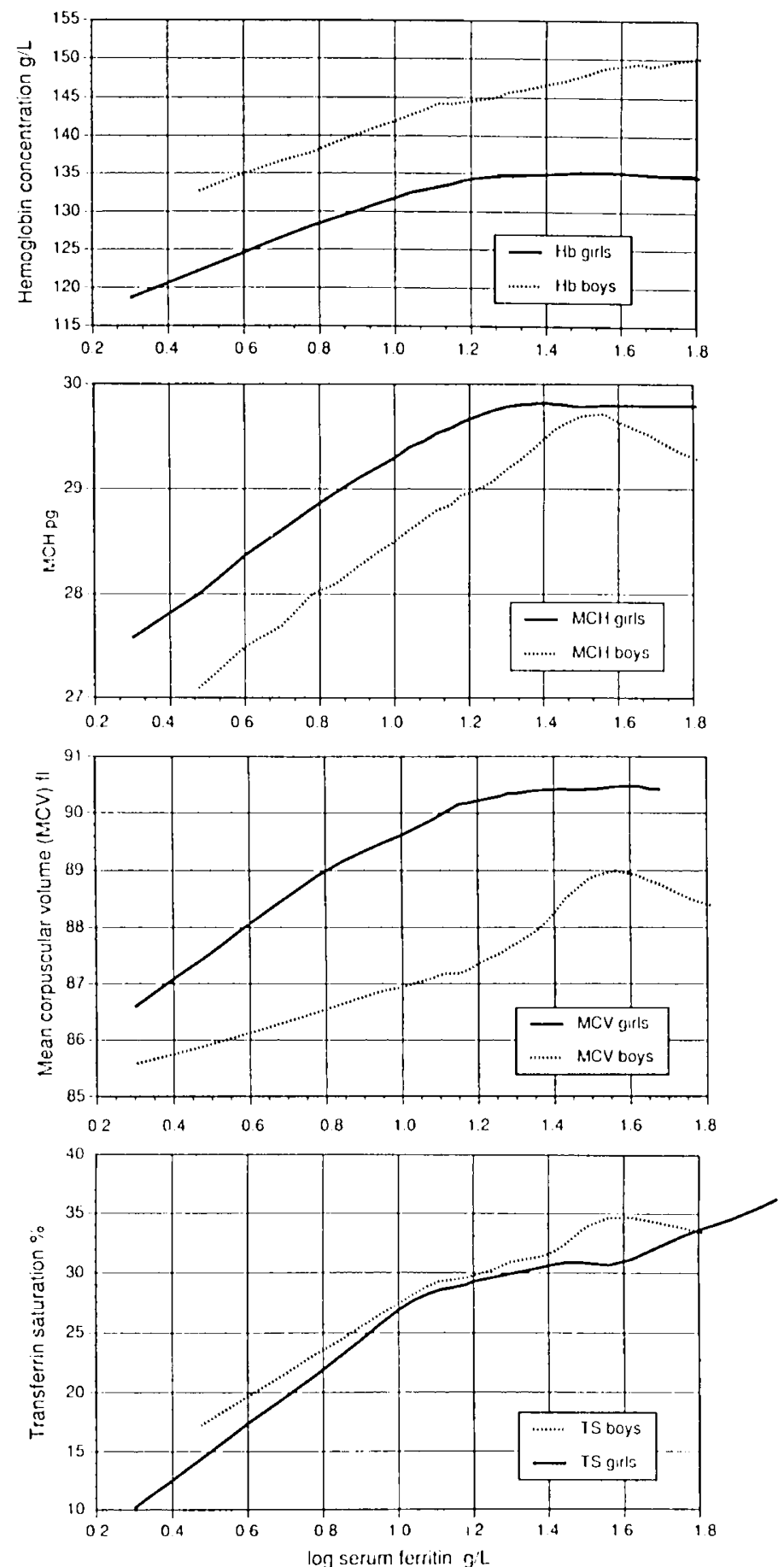

Fig. 4. The relationship between $\log \mathrm{SF}$ and $\mathrm{Hb}$ concentration, $\mathrm{MCH}$. $\mathrm{MCV}$, and TS in girls and boys using a locally weighted least square error fit (for explanation, see text). $\log S F 16=1.2: 20=1.3: 30=1.48$; $40=1.6$.

established by the absence or presence of reticuloendothelial iron in technically adequate bone marrow smears. The prevalence figures of iron deficiency observed in girls and boys ( 40 and $15 \%$, respectively) were high using the cutoff value of SF $<16 \mu \mathrm{g} / \mathrm{L}$. The possibility that this value might be too high was therefore carefully considered. The relationship between SF and iron stores might, for example, be different in adolescents and in adults. This hypothesis was examined by relating $\mathrm{SF}$ in adults and adolescents to another independent parameter. TS, expected to be related to the size of the iron stores. It is well established that TS is very high in states of iron overload and low in severe iron 
Table 4. Prevalence of recent infection in adolescents grouped according to SF interval

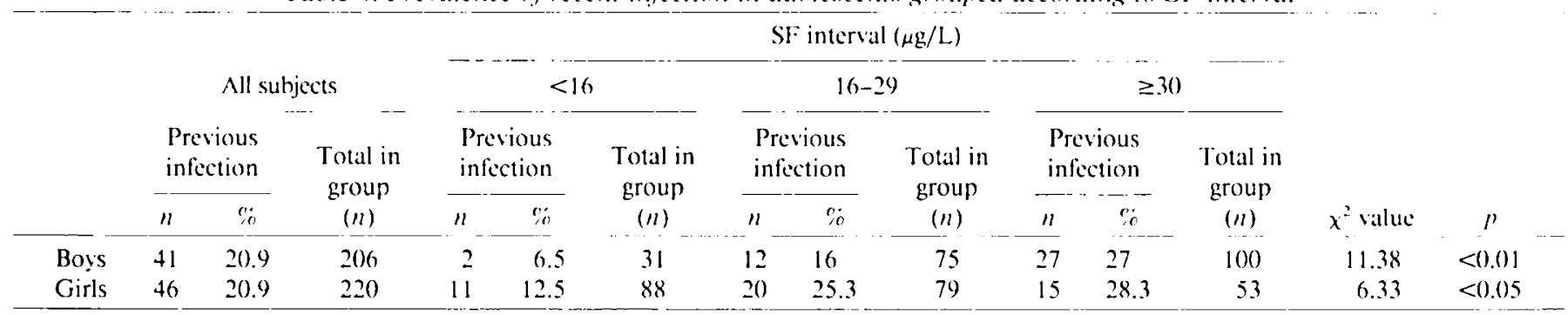

deficiency anemia. The correlation between TS and SF was highly significant in the boys, the girls, and the adult women ( $p$ $<0.0001)$. As shown in Figure 5, the regression lines for the relationship between TS and SF were very similar in the adult women and in the boys and girls and there was no statistically significant difference between the three regression lines. The relationship between SF and iron stores is thus very probably the same in adolescents and adults and implies that the same cutof value for SF should be used. The validity of the cutoff value used presently is also supported by the independent findings that SF values below this cutoff value were associated with signs of an iron-deficient erythropoiesis. The balance of evidence thus implies that the prevalence of iron deficiency in adolescents, in fact. is very high.

Theoretically, the absence of iron stores per se may not be associated with any negative effects as long as iron absorption can balance the physiologic requirements needed to cover iron losses and growth. Iron deficiency can be considered to occur when there is an insufficient supply of iron to tissues, i.c. when insufficient amounts of iron-transferrin reach the transferrin receptors on various cell surfaces. To establish that iron deficiency is really present, one would thus require both depletion of iron stores and signs of a compromised supply of iron to an easily accessible tissue. such as red cells. This is difficult to establish in the individual subject due to the previously mentioned marked overlap in normal and iron-deficient subjects between the distributions of various parameters that are influenced by the iron supply to the erythron such as $\mathrm{Hb}$ and red cell indices.

It was thus important to examine at what SF concentration there were signs of an iron-deficient erythropoiesis. The increase in $\mathrm{MCH}, \mathrm{MCV}$, and $\mathrm{Hb}$ concentration with increasing SF certainly indicates that the critical point for the supply of iron to the erythron is positioned above the SF value $16 \mu \mathrm{g} / \mathrm{L}$ (Tables 2

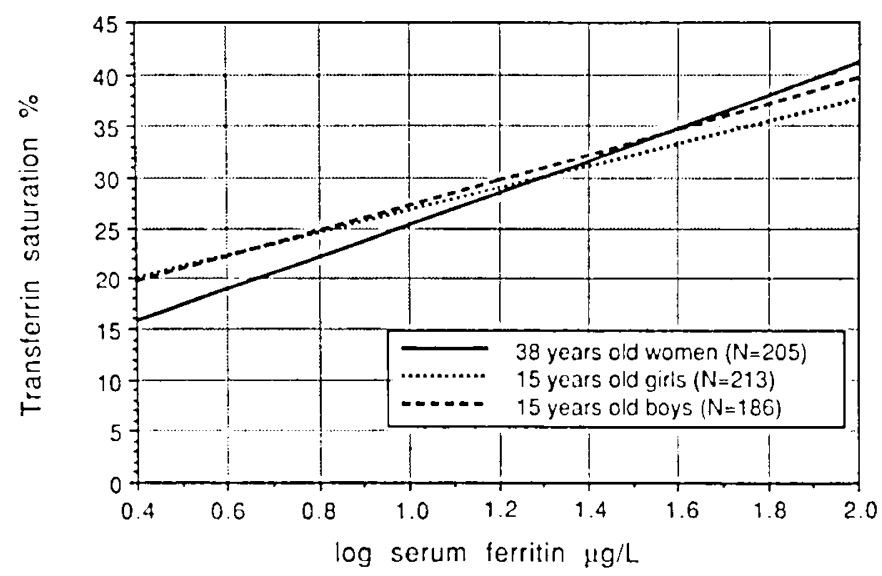

Fig. 5. Regression lines for the relationship between TS and log SF concentration in the present material of girls and boys and a sample of 38 -y-old women previously studied (see text). All correlation coefficients were highly significant $(p)<0.0(0) 1)$, and there was no statistically significant differences between slopes or intercepts of the three lines. and 3). The regression analyses of the hematologic parameters at different SF deciles more strongly suggest that iron-deficient erythropoiesis starts well above a SF level of $16 \mu \mathrm{g} / \mathrm{L}$. Moreover, the graphical analyses based on a locally weighted least square method showed that the decrease in $\mathrm{Hb}$ concentration. $\mathrm{MCH}$, and MCV started at an SF concentration of about $20 \mu \mathrm{g} / \mathrm{L}$ in girls and about $30-40 \mu \mathrm{g} / \mathrm{L}$ in boys.

The findings of signs of an iron-deficient erythropoiesis at SF levels well above the selected cutoff value may simply be explained by individual differences in the SF level at which iron stores are exhausted. The unexpected observations that differences in the severity of iron depletion (Hb concentration, $\mathrm{MCH}$. $\mathrm{MCV}$, and TS) were associated with statistically significant differences in the concentration of subnormal SF values would suggest that iron stores might never be completely exhausted. not even in severe iron deficiency anemia. This conceptually quite different explanation would fit with the fact that some ferritin can always be demonstrated biochemically in the liver and bone marrow, even when iron deficiency anemia is present. and no stainable iron can be demonstrated microscopically (35). This hypothesis implies that the release of iron from stores becomes successively more difficult and is influenced by the amounts of iron remaining in stores. This hypothesis would also be consistent with the strong relationship between iron stores, $\mathrm{SF}$, and TS observed from severe iron deficiency anemia to iron overload.

The present findings that hematologic parameters start to decrease at SF values $>16 \mu \mathrm{g} / \mathrm{L}$ strongly suggest that iron stores are depleted or negligible at the cutoff value used for $\mathrm{SF}(<16$ $\mu \mathrm{g} / \mathrm{L}$ ) and that at this point the erythropoiesis is limited by an insufficient supply of iron. Therefore, an SF value $<16 \mu \mathrm{g} / \mathrm{L}$ can be validly used as the sole indicator of iron deficiency. This will certainly simplify the diagnosis of iron deficiency, especially in epidemiologic studies. In clinical practice, however, it is important to emphasize that an SF value $>15 \mu \mathrm{g} / \mathrm{L}$ cannot be used to exclude deficiency. One reason is that there is a certain probability that patients with higher SF values, especially in the range of $16-30 \mu \mathrm{g} / \mathrm{L}$, are iron deficient.

The other fact to be considered is that in patients with iron deficiency, SF values may falsely be too high due to recent infections, inflammatory diseases, liver diseases, or starvation. Several studies have shown that common infections may increase the SF level (32-34). This was also illustrated by the present findings that the proportions of subjects with a recent infection were higher in groups II and III with the higher SF values, suggesting that infections may have caused a shift of SF toward higher values resulting in some underestimation of the prevalence of iron deficiency (Table 4).

The iron status in different populations can be validly studied by comparing the distributions of the SF concentration in representative samples. The figures for 15 -y-old girls in Canada (Nutrition Canada National Survey) were estimates obtained by interpolation from an enlarged published graph (18). The distributions of SF in girls were rather similar in Canada. the United States [N-HANES II study (30)]. and Sweden (present sample), whereas the ferritin values were higher in 15-y-old girls in Australia [National Dietary Survey of Schoolchildren (31)]. The 
prevalence of iron deficiency in the 15- to 16-y-old girls in the present sample was $40 \%$ ( 88 of 220 ) based on a cutoff value for $\mathrm{SF}$ of $<16 \mu \mathrm{g} / \mathrm{L}$. Corresponding figures for girls in the United States, Canada, and Australia, using the same cutoff value, would be $42 \%, 40 \%$, and $23 \%$. The reason for the lower prevalence of iron deficiency in the Australian girls is not known.

In boys, the SF values were consistently lower in Canada except at the 90th and 95th percentiles. At the lower end of the distribution curves, up to the 25th percentile, the distributions in the United States, Australia, and Sweden were rather similar. The prevalence of iron deficiency in the 15- to 16-y-old boys in the present Swedish sample (SF $<16 \mu \mathrm{g} / \mathrm{L}$ ) was $15 \%$ (31 of 207). Corresponding figures for boys in the United States, Australia, and Canada were $10 \%, 9 \%$, and $32 \%$. It should be mentioned that, in the Canadian study, 32 of 98 boys $(32.7 \%)$ had an SF value below $15 \mu \mathrm{g} / \mathrm{L}$ in the whole age group, $10-19 \mathrm{y}$. The reason for the divergent, higher prevalence of iron deficiency in Canadian boys is unknown. It is of interest that another study in another region of Canada (Quebec) also reported similarly high figures of iron deficiency for both boys and girls. A weighed mean prevalence was $38 \%$ in 189 boys aged $13-18$ y, and $39.5 \%$ in 180 girls (36).

Several bias factors may influence the validity of comparisons of the prevalence of iron deficiency in different groups examined by different laboratories. Examples are the effects of sampling methods, seasonal variations, and differences in infection rate. Previously, an important source of error was differences between calibrators used in different kits for SF determinations. An international standard was introduced in 1981 by the International Committee for Standardization in Haematology, made available by the National Institute for Biological Standards and Control, a WHO International Laboratory for Biological Standards in London. Since then, most, but possibly not all, laboratories have been using methods calibrated with this standard. Even before this time, however, some participating laboratories were using adequate standards.

Present results suggest that some of the previous methods used in estimating the prevalence of iron deficiency, for example in the N-HANES II study, led to a considerable underestimation of the condition $(37,38)$. In the previously mentioned sample of 38-y-old women, the distribution of SF in those with no stainable iron in their bone marrow smears indicated that only about $60 \%$ of the iron-deficient subjects would be correctly classified as iron deficient at the cutoff value of $<12 \mu \mathrm{g} / \mathrm{L}$ for SF used in the $\mathrm{N}$ HANES II study. It was also found that if multiple hematologic criteria of iron deficiency had to be fulfilled to establish the diagnosis, the degree of underestimation of the true prevalence of iron deficiency would be even greater (26).

Iron requirements in adolescents are high, and much iron is needed to cover basal iron losses, requirements for growth. and, for girls, menstrual iron losses as well. Based on extensive longitudinal studies on growth and development in children, especially in Britain $(39,40)$ and Sweden $(41)$, the maximal wholeyear velocity standard for both weight and height in boys is seen around the age of 13-14 y. It has been suggested that the growth spurt in boys should be of short duration (42). In both the British and Swedish materials, however, there was a continued marked growth in both height and weight even 3 y after attaining the maximal growth velocities. Sexual maturation is associated with an increase in $\mathrm{Hb}$ concentration with a continuous, marked increase between the age of 13 and 16 y (43). About 4-5 times more iron is required for this $\mathrm{Hb}$ mass increase than for the growth of other tissues. Total iron requirements in boys are thus high for a period of 3-4 y. In girls, the growth spurt is seen about $1-2$ y earlier than in boys and the 50 th percentile maximal height is attained at about the age of 15-16 y, whereas body weight continues to increase. The average age for menarche in Sweden is around $13 \mathrm{y}(\mathrm{SD} \pm 1 \mathrm{y})$ or about $1 \mathrm{y}$ after peak growth. In the present material, eight of the 220 girls $(3.6 \%$ ) had not yet had their menarche. The average age of menarche was 12.9 y (SD
$1.0 \mathrm{y})$. In single individuals, growth and iron requirements may be very high and of shorter duration. For most adolescents, however, total iron requirements are high for a considerable period of time. This conclusion is supported by findings in a longitudinal study of SF in adolescent girls (44).

It may seem paradoxical that a nutrient deficiency disorder should be common among adolescents in highly industrialized countries with an excess of foods. It should be remembered, however, that although iron requirements are very probably the same today as they were for our ancestors, the food intake is much lower with our present low-energy life-style. Moreover, the composition of our diet has not been sufficiently adjusted to this life-style. Available information suggests that our ancestors had not only a higher intake of energy and iron but probably also a higher bioavailability of their dietary iron with a higher content of animal protein and ascorbic acid (45).

Present findings strongly suggest that more emphasis must be placed on the prevention of iron deficiency. Adolescents are one of the important target groups who must be better covered by intervention measures such as school lunch programs and the adequate iron fortification of foods even in highly industrialized countries.

\section{RETERENCES}

1. Lozoff B 1988 Bchavioral alterations in iron deficiency. Adv Pediatr 35 $331-360$

2. Walter T. Kovalskys J. Stekel A 1983 Effect of mild iron deficiency on infant mental develonmental scores. J Pediatr 102:519-522

3. Dobbing $J$ (ed) 1990 Brain. Behaviour and Iron in the Infant Diet. Springer Verlag Lid. London

4. Scrimshaw NS 1084 Functional consequences of iron deficiency in human populations. J Nutr Sci Vitaminol 30:47-63

5. Hallgren B. Sourander P 1958 The effect of age on the non-haemin iron in the human brain. $J$ Neurochem $3: 41-51$

6. Dallman PR. Siimes MA, Mauies IC 1975 Brain iron: persistent deficiency following short-term iron deprivation in the young rat. Br J Hatematol 31:209-215

7. Dallman PR 1986 Biochemical hasis for the manifestations of iron deficiency Annu Rev Nutr 6:13-40

8. Youdim MBH (ed) l988 Brain Iron. Neurochemical and Behavioural Aspects. Taylor \& Francis. London pp 89-114

9. FAO/WHO Joint Expert Consultation Report 1988 Requirements of vitamin $A$, iron. folate and vitamin $B_{12}$. FAO Food and Nutrition Series 23, Rome

10. Hallberg L. Rossander-Hultin I. 1991 Iron requirements in menstruating Women. Am J Clin Nutr 54:1047-1058

11. Dallman PR. Siimes MA. Stekcl A 1980 Iron deficiency in infancy and childhood. Am J Clin Nutr 33:86-118

12. Jacobs $A$. Miller F. Worwood M. Beamish MR, Wardrop CA 1972 Ferritin in the serum of nornal subjects and patients with iron deficiency and iron overload. Br Mled J 4:206-208

13. Walters GO. Miller FM, Worwood M 1973 Serum ferritin concentration and iron stores in normal subjects. J Clin Pathol 26:770-772

14. Lundberg P-A. Lindstedt G, Andersson T. Branegiord B, Lundquister G 1984 Increase in serum ferritin concentration induced by fasting. Clin Chem $30: 161-163$

15. Cook JD. Lipschitz DA. Miles LEM. Finch CA 1974 Serum ferritin as a measure of iron stores in normal subjects. An J Clin Nutr 27:681-687

16. Sorbic J, Valberg LS, Corbett WEN, Ludwig J 1975 Serum ferritin, cobalt excretion and bedy iron status. Can Med Assoc J 112:1173-1178

17. Leyland MJ. Ganguli PC. Delamore IW $1975 \mathrm{Immunoradiometric} \mathrm{assiy} \mathrm{for}$ ferritin in human serum. Scand J llacmatol 14:385-392

18. Valherg LS. Sorbic J. Ludwig J. Pelleties O 1976 Serum ferritin and the iron status of Canadians. Can Med Assoc J |1 1:+17-421

19. Barnett MD. Gordon YB, Amess JAL. Mollin DL 1978 Measurement of ferritin in scrum by radioimmunoassay. J Clin P'athol 31:742-748

20. Guillehaud J, Barnett MD. Gordon Y'B 1979 Plasma ferritin as an index of iron deficiency in women using intrauterine devices. Br J Obstet Gynateol $86: 51-55$

21. Mazza J, Barr R, MCDonald J, Valberg LS 1978 Usefulness of the serum ferritin concentration in the detection of iron deficiency in a general hospital. Can Med Assoc J 119:884-886

22. Heinrich HC 1979 Diagnostischer Wert der Radiocisen-Absorption und des Serum-Ferritins bei Eisenmangel und Eisenüberladung. Ned Welt 30:89-97

23. Gordon RA. Hamilton RW, Demers LM, Miller D 1981 Serum ferritin level as index of iron stores. Pennsyly Med 84:54-56

24. Milman N. Strandberg Pedersen N. Visfecldt J 1983 Serum ferritin in health Danes: redation to marrow hatemosiderin iron stores. Dan Med Bull 30:115120

25. Harju F. Pakarinen A. Larmi T 1984 A comparison between serum ferritin concentration and the amount of bone marrow stainable iron. Scand J Clin Lab Invest 44:555-556 
26. Hallberg L. Bengtsson C. Lapidus L. Lindstedt G, Lundherg PA. Hulthen I. 1993 Screening for iron deficiency: an analysis based on bone marrow examinations and serum ferritin determinations in a sample of women. $\mathrm{Br}$ J Hatematol (in press)

27. Milsom I. Rybo G, lindstedi G 1990 The influence of copper surface area on menstrual blood loss and iron status in women fitted with an IUID. Contraception $+1: 27 !-281$

28. Ichida T. Osaka T, Kojima K 1968 A simple method for the determination of serum iron. Clin Chim Acta 22:271-275

29. Chambers JM. Cleveland WS, Kleiner B. Tukey PA 1983 Graphical Methods for Data Analisis. Duxbury Press. Belmonte, $C A$

30. Pilch S.I. Senti FR (eds) 1984 Assessment of the iron nutritional status of the US population hased on data collected in the second National Health and Nutrition Examination Survey, 1976-1980. Prepared for the Food and Drug Administration under contraet no. FDA 223-83-2384. Bethesda, MD. Lifie Sciences Rescarch Omice. Federation of American Societies for Experimental Biology

31. English RM, Bennett SA 1990 Iron status of Australian children. Med J Aust $152: 582-586$

32. Siimes M1A. Addego JE. Daliman PR 1974 Ferritin in serum: diagnosis of iron deficiency and iron overload in infants and children. Blood 4.581-590)

33. Lipschitz. DA. Cook JD. Finch CA 1974 A clinical evaluation of serum ferritin as an index of iron stores. N Engl J Med 290:1213-1216

34. Birgegard G. Hallgren R. Killander A. Stromberg A. Venge P. Wide L 1978 Serum ferritin during infection. Scand J Haematol 21:333-340

35. Weinfeld $A 1965$ Storage iron in man. Acta Med Scand Suppl 427:1-155
36. Seoane NA. Roberge AF. Page M. Allard C, Bouchard C 1985 Selected indices of iron status in adolescents. J Can I iet Assoc +6:298-303

37. Dallman PR. Y'ip R. Johnson C 1984 Prevalence and causes of anemia in the United Stales, 1976 to 1980. Am J Clin Nutr 39:437-445

38. Expert Scientific Working Group 1985 Summary of a report on assessment of the iron nutritional status of the United States. Am J Clin Nutr $+3: 1318-$ 1330

39. Tanner JM. Whitchouse RH. Takaishi M 1966 Standards from birth to maturity for height. weight, height velocity, and weight velocity: British children. 1965. Part 1. Arch Dis Child 41:454-471

40. Tanner JM. Whitchouse RH, Takaishi M 1966 Standards from birth to maturity for height, weight, height velocity, and weight velocity: British children, 1965. Par 11. Arch Dis (hild +1:6 1.3-6.32

4l. Karlberg P. Taranger J, Engstrom I. Lichtenstein H. Svennberg-Redegren 1976 The somatic development of children in a Swedish urhan community Acta Paediatr Scand Suppl 258:5-147

42. Dallman PR 1992 Changing iron needs from hirth through adolesecnce. In: Fomon SJ. Zlotkin S (eds) Nutritional Anemias. Nestle Nutrition Wurhshop Series, Vol 30. Raven Press, New York. pn 29-36

43. Dallman PR. Siimes MA 1979 Percentile curses for hemoglobin and red cell volume in infancy and childhood. J Pediatr 94:26-31

44. Kagagimori S. Fujita T. Naruse Y'. Kurosawa Y'. Watanabe 11988 A longitudinal study of serum ferritin concentration during the female adolescent growth spuri. Ann llum Biol 15:413-419

45. Eaton SB. Konner M 1985 Paleolithic nutrition: a consideration of its nature and current implications. N Engl J Med 312:283-289 